\title{
Platelet Interaction with Rabbit Subendothelium in von Willebrand's Disease: Altered Thrombus Formation Distinct from Defective Platelet Adhesion
}

\author{
Vincent T. Turitto, Harvey J. Weiss, \\ and Hans R. Baumgartner \\ Department of Medicine, Division of Hematology-Oncology, \\ St. Luke's-Roosevelt Hospital Center and Columbia University \\ College of Physicians and Surgeons, New York, New York 10019, \\ and Department of Pharmaceutical Research, \\ F. Hoffmann-La Roche \& Co., Ltd., Basel, Switzerland
}

bstract. Blood interaction with the subendothelium of rabbit aorta was investigated in an annular perfusion chamber using patients with von Willebrand's disease, hemophilia, and afibrinogenemia. The vessels were exposed to nonanticoagulated blood for a range of flow conditions (wall shear rates of $650-3,300 \mathrm{~s}^{-1}$ ) and exposure times $(1.5-10 \mathrm{~min})$. The resultant platelet and fibrin interaction was quantified by the use of several morphometric techniques, one of which was developed to measure more precisely the dimensions (height and volume) of platelet thrombi attached to the subendothelium.

A major finding was that under flow conditions in which little or no defect in platelet adhesion was observed in von Willebrand's disease, platelet thrombus height and volume in this disorder were significantly reduced as compared with normal controls or patients with hemophilia. Thus, Factor VIII/von Willebrand factor (VIII/VWF) may mediate not only the adhesion of platelets to subendothelium but also platelet-platelet attachments necessary for normal thrombus development. The level of Factor VIII:coagulant activity (VIII: C) was also observed to influence the resultant thrombus height and volume deposited on subendothelium, presumably through the generation of thrombin or some

This work was done in part during Dr. Turitto's tenure as an Established Investigator of the American Heart Association.

Received for publication 25 October 1983 and in revised form 2 July 1984.

J. Clin. Invest.

(C) The American Society for Clinical Investigation, Inc.

$0021-9738 / 84 / 11 / 1730 / 12 \$ 1.00$

Volume 74, November 1984, 1730-1741 other procoagulant factor preceding fibrin formation, since normal values of thrombus dimensions were always observed in a patient with a fibrinogen deficiency. The influence of VIII:C became greater as shear rate was reduced, whereas as shear rate was increased, VIII/VWF was more dominant in determining the resultant platelet deposition on subendothelium.

Thus, the deficiencies of VIII:C and VIII/VWF in hemophilia and von Willebrand's disease can lead to various abnormalities in platelet and fibrin association with subendothelium. The importance of a particular deficiency will depend strongly on the local blood flow conditions.

\section{Introduction}

Previous studies have indicated that the bleeding associated with von Willebrand's disease may be due to a defect in the ability of platelets to attach to the vascular subendothelium $(1,2)$. The extent of subendothelial surface covered with platelet thrombi in those studies was diminished; however, it was suggested that this reduction was due to the abnormal platelet adhesion, since $(a)$ platelet adhesion precedes and is necessary for thrombus formation, and $(b)$ platelets from patients with von Willebrand's disease that had adhered to the subendothelium formed platelet thrombi to the same extent as those from controls $(1,2)$.

However, it is well known that platelets from patients with von Willebrand's disease show diminished aggregation with ristocetin (3) and reduced retention (largely a measure of platelet aggregate formation) in packed bead columns $(4,5)$. Also, it has recently been reported that platelets from patients with von Willebrand's disease aggregate with a microfibrillar extract only in the presence of added von Willebrand factor (6). Thus, a defect in platelet-platelet interaction might also be possible in this disorder. 
The defect in the ability of platelets from patients with von Willebrand's disease to adhere to subendothelium has been shown to increase with increasing blood shear rate (2); the reduced level of platelet adhesion on subendothelium precludes a controlled study of the nature of the plateletplatelet attachment process at high shear conditions. Thus, lower shear conditions for which the defect in adhesion was minimized were selected in order to investigate better platelet aggregate formation induced by subendothelium in von Willebrand's disease. In addition, a morphometric technique for analyzing thrombus dimensions was used to measure more precisely changes in thrombus dimensions in these studies (7).

\section{Methods}

Procedure. An annular perfusion chamber was used to expose subendothelium to whole blood under controlled flow conditions. The procedure has been previously described $(2,7,8)$. In brief, nonanticoagulated blood from the antecubital vein was drawn directly through an infusion set (Butterfly; Abbott Hospitals Inc., North Chicago, IL) over subendothelium from everted rabbit aorta completely denuded of endothelial cells. Vessels were stored in $0.2 \mathrm{M}$ Tris buffer at $4^{\circ} \mathrm{C}$ for $7-28 \mathrm{~d}$ before use. Blood was maintained at $37^{\circ} \mathrm{C}$ by a water bath and not recirculated; flow through the chamber was controlled by a peristaltic pump (Holter; Extracorporeal Medical Specialties, Inc., King of Prussia, PA). After exposure, vessel segments were rinsed with phosphate-buffered saline and fixed with glutaraldehyde under perfusion conditions (2).

Perfusion conditions. Blood was withdrawn from the vein through the small perfusion chamber at three different flow rates: $50 \mathrm{ml} / \mathrm{min}$ for $2 \mathrm{~min} ; 20 \mathrm{ml} / \mathrm{min}$ for $1.5,3.5$, and $10 \mathrm{~min}$; and $10 \mathrm{ml} / \mathrm{min}$ for 5 and $10 \mathrm{~min}$. These flow rates correspond to blood shear rates at the vessel surface of $3,300,1,300$, and $650 \mathrm{~s}^{-1}$, respectively. These shear conditions are characteristic of flow in the smaller arteries and the microcirculation (9). Calculation of the shear rate in the small chamber has been reported previously $(2,10)$.

Morphological evaluation. Evaluation of platelet interaction with subendothelium involved two separate microscopical techniques which were both performed on the same cross-sectional area of vessel segment. Vessel segments, $20 \mathrm{~mm}$ in length, were divided into six equal parts after the removal of $1 \mathrm{~mm}$ from each end. Vessels were dehydrated and embedded in epoxy resin as previously described ( 2 , 8). Semithin sections, $\sim 0.8 \mu \mathrm{m}$ in thickness were prepared and all evaluations were determined at a single axial position located $\sim 10$ $\mathrm{mm}$ from the proximal end of the original segment. A standard morphometric technique was used to evaluate the platelet-subendothelial interactions (11). In this technique, platelet interaction with subendothelium was evaluated as $(a)$ contact $(C)$ : platelets attached but not intimately bound to the subendothelium; $(b)$ spread (S): platelets closely adherent to subendothelium, including small aggregates less than $5 \mu \mathrm{m}$ in height; or $(c)$ thrombus (T): platelet aggregates extending $>5 \mu \mathrm{m}$ into the lumen. The percentage of surface coverage with platelet thrombi is defined as $\mathrm{T}$ divided by the total number of surface evaluations. Platelet adhesion $(C+S)$ is the sum of all platelets attached to the surface divided by the number of evaluations. Coverage of the subendothelial surface or the platelet surface with fibrin $(F)$ was determined at $10-\mu \mathrm{m}$ intervals and expressed as a percentage of the total number of evaluations $\sim 1,000(7,8)$. Total surface coverage with fibrin is simply the numerical sum of the subendothelial and platelet coverage. Identity of fibrin was demonstrated by electron microscopy showing apparent banding of $\sim 230 \AA$ of longitudinally cut fibrin strands.

A second morphometric technique was used to investigate more precisely the extent and shape of platelet aggregates formed on subendothelium. Vessel sections previously evaluated by the standard technique were projected onto the recording plate of a manual optical picture analysis system (MOP/AMOI; Kontron Elektronik GmbH A.G., Switzerland). The total cross-sectional area of the deposited thrombi was determined mathematically by the MOP system from individual traces of the perimeter of each thrombus in the projected section. Normalization of the thrombus area by the vessel circumference (perimeter of the projected vessel section) results in the thrombus cross-sectional area per unit length of vessel segment circumference, which corresponds stereologically to the total volume of the platelet thrombi associated with a unit surface area of subendothelium (7). The thrombus height distribution was determined by tracing the height of all thrombi in the cross-sectional view. The distribution is expressed as the total number of thrombi of heights located in the following ranges: $5-10,10-20,20-40$, and $>40 \mu \mathrm{m}$ (7). The maximum thrombus height is defined as the mean of the three highest values obtained from the thrombus height distribution.

Factor VIII-related values. The values reported for the various Factor VIII-related properties were obtained by previously described methods and included. Factor VIII-coagulant activity (VIII:C) ${ }^{1}$ (12); Factor VIII-related antigen (VIIIR:Ag) by immunoradiometric assay (IRMA) (12) (performed by Dr. Leon Hoyer, University of Connecticut School of Medicine, Department of Medicine, Farmington, CT) and Laurell electro-immunoassay (EIA) (13); and Factor VIII-related ristocetin cofactor activity (VIIIR:RCo) (12).

\section{Subjects}

Normal subjects. This group consisted of 27 male and female hospital personnel, 21 to $45 \mathrm{yr}$ of age, who had not ingested aspirin for a period of at least $1 \mathrm{wk}$ before study.

von Willebrand's disease. Seven patients with von Willebrand's disease who had not been transfused for at least 1 mo were studied. Patients V.M., C.M., and D.R. are three previously studied subjects $(2,12-14)$ who have the severe classical forms of the disease, with undetectable levels of VIIIR:Ag and VIIIR:RCo, and VIII:C values of 1-2 U/dl on multiple testing (Table I). Two other patients, M.M. and W.D., with the same type of von Willebrand's disease were previously diagnosed by Drs. Majorie Zucker (New York University) and Richard Lipton (Long Island Jewish Hospital), respectively, and on the day of study had undetectable levels of VIIIR:Ag (by EIA) and VIIIR:RCo, and their VIII:C levels were 5 and $8 \mathrm{U} / \mathrm{dl}$, respectively (Table I). Patients P.H. and A.S. (Table I) have the findings characteristic of Type IIA von Willebrand's disease patients (13), with markedly decreased values of VIIIR:Ag (by IRMA and EIA) and VIIIR:RCo, and VIII:C values of 9-15 and 23-30 U/dl, respectively, upon multiple testing. P.H. has been previously shown to have a striking absence of high molecular weight multimers of Factor VIII/von Willebrand factor (VIII/VWF) on sodium dodecyl sulfate-agarose-acrylamide gel electrophoresis and an increased mobility of VIIIR:Ag on radiocrossed

1. Abbreviations used in this paper: EIA, electro-immunoassay; VIII:C, Factor VIII coagulant activity; VIIIR:Ag, Factor VIII-related antigen; VIIIR:RCo, Factor VIII-related ristocetin cofactor activity; VIII/VWF, Factor VIII/von Willebrand factor; IRMA, immunoradiometric assay. 


\begin{tabular}{|c|c|c|c|c|c|}
\hline \multirow[b]{3}{*}{ Subjects } & \multirow[b]{3}{*}{ Age, Sex } & \multirow{2}{*}{\multicolumn{2}{|c|}{$\begin{array}{l}\text { VIII/VWF values } \\
\text { VIIIR:Ag }\end{array}$}} & \multirow[b]{3}{*}{ VIIIR:RCo } & \multirow[b]{3}{*}{ VIII:C } \\
\hline & & & & & \\
\hline & & IRMA & EIA & & \\
\hline \multicolumn{6}{|l|}{ Severe VWD } \\
\hline V.M. & $34, \mathrm{~F}$ & $<0.3$ & $<6$ & $<3$ & $1-2$ \\
\hline C.M. & $35, \mathrm{M}$ & $<0.3$ & $<6$ & $<3$ & $1-2$ \\
\hline D.R. & $32, \mathrm{~F}$ & $<0.3$ & $<6$ & $<3$ & $1-2$ \\
\hline M.M. & $35, \mathrm{~F}$ & 1.6 & $<6$ & $<3$ & 5 \\
\hline W.D. & $38, \mathrm{M}$ & 4.3 & $<6$ & $<3$ & 8 \\
\hline \multicolumn{6}{|l|}{ Type IIA VWD } \\
\hline P.H. & $82, \mathrm{M}$ & 4 & 17 & $3-9$ & $9-15$ \\
\hline A.S. & $45, \mathrm{~F}$ & $2-7$ & $<6$ & $5-8$ & $23-30$ \\
\hline Hemophilia $(n=11)$ & $18-55, \mathrm{M}$ & ND & $146 \pm 18^{*}$ & $142 \pm 16^{*}$ & mostly $<1$ (see text) \\
\hline Normal subjects $(n=27)$ & $21-45, \mathrm{M} / \mathrm{F}$ & $50-180$ & $55-161$ & $50-150$ & $50-150$ \\
\hline
\end{tabular}

Values are given in units per deciliter. VWD, von Willebrand's disease. * Mean values \pm SE compiled on eight subjects only.

immunoelectrophoresis (13), and similar findings have been obtained in studies on patient A.S. (kindly performed by Dr. Dominique Meyer, Hôpital Bicêtre, France).

Hemophilia. 11 patients with classical hemophilia were used in the study. The values of VIII:C were $<1 \mathrm{U} / \mathrm{dl}$ in 7 patients, $1-2 \mathrm{U} / \mathrm{dl}$ in 3 patients, and $5 \mathrm{U} / \mathrm{dl}$ in one patient. The VIIIR:Ag (by EIA) value in a subgroup of these patients $(n=8)$ was $146 \pm 18 U / \mathrm{dl}$ and the VIIIR:RCo values were $142 \pm 16$.

Afibrinogenemia. One patient with a congenital deficiency in fibrinogen will be referred to as having afibrinogenemia, although a small amount $(3 \mu \mathrm{g} / \mathrm{ml}$, normal values $1,500-3,500)$ of immunologically detectable fibrinogen has been found in his plasma (15). Previous studies on this patient (16) have demonstrated diminished platelet aggregation by ADP and epinephrine in citrated platelet-rich plasma. These abnormalities, as well as the prolonged bleeding time, were corrected by transfusion of fibrinogen (16) and, in vitro, by addition of fibrinogen in concentrations of $10-20 \mathrm{mg} / \mathrm{dl}$.

Blood values. Platelet counts and hematocrit were determined on blood collected into EDTA before each perfusion experiment. Platelet counts were evaluated by an electronic counting device (model S, Coulter Electronics Inc., Hialeah, FL). For the normal subjects used in this study, the average value was $250,000 / \mu 1$ with a range of $172-$ $336,000 / \mu$ l. All subjects with platelet counts $>350,000 / \mu \mathrm{l}$ were excluded from the normal control group. The average value for platelet count in the von Willebrand's patients was $262,000 / \mu \mathrm{l}(160-345,000 / \mu \mathrm{l})$ and in hemophilic patients, $258,000 / \mu \mathrm{l}(186-351,000 / \mu \mathrm{l})$. The average values for hematocrit were $41 \%(34-51 \%)$ in control subjects, $41 \%$ $(37-47 \%)$ in von Willebrand's patients, and $44 \%(41-48 \%)$ in hemophilic patients.

Statistical significance. Significance was determined by the standard $t$ test without the assumption being made that patient and control subjects had equivalent population variances (17). Significance levels are indicated only for the major variables of interest, namely, fibrin formation, thrombus volume and thrombus height, and platelet adhesion, in order to avoid spurious significance due to comparison of multiple measurements. In addition, values are considered significantly different only for $P<0.02$.

\section{Results}

In the present investigation a range of experimental flow conditions for studying blood-vessel wall interaction has been investigated in normal controls and patients with von Willebrand's disease. Blood from patients with severe classical hemophilia and afibrinogenemia was also studied.

Blood flow of $50 \mathrm{ml} / \mathrm{min}$ (wall shear rate of $3,300 \mathrm{~s}^{-1}$ ). Values of platelet adhesion $(C+S)$ from patients with von Willebrand's disease were significantly lower $(P<0.01)$ than those from either normal controls or patients with severe hemophilia (Table II).

An evaluation of thrombus dimensions is given in Table II $B$. As expected from the decreased levels of platelet adhesion, the von Willebrand's patients exhibit severely decreased values of thrombus volume $(P<0.01)$ and maximum thrombus height $(P<0.001)$ as compared with normal controls or hemophilic patients. In both the hemophilic patients and the fibrinogen-deficient patient, the thrombus height distribution, the thrombus volume, and the maximum thrombus height were not significantly different from those in normal controls. The thrombus height distribution in von Willebrand's disease patients was depressed at all values of thrombus height, and thrombi never grew $>30 \mu \mathrm{m}$ in height under these conditions, as compared with peak heights of $80-140 \mu \mathrm{m}$ in normal controls.

Blood flow of $40 \mathrm{ml} / \mathrm{min}$ (wall shear rate of 2,600 s-1). At slightly reduced wall shear rates, values of platelet adhesion (C $+\mathrm{S})$, as indicated in Table III, continue to be depressed ( $P$ 
Table II. Interaction of Blood with Subendothelium: Blood Flowing at $50 \mathrm{ml} / \mathrm{min}\left(3,300 \mathrm{~s}^{-1}\right)$ for $2 \mathrm{~min}$

A. Standard morphometric measurements

\begin{tabular}{|c|c|c|c|c|c|}
\hline \multirow[b]{2}{*}{ Subjects } & \multirow[b]{2}{*}{$\begin{array}{l}\text { Platelet adhesion* } \\
(C+\text { S) }\end{array}$} & \multirow[b]{2}{*}{$\begin{array}{l}\text { Surface coverage } \\
\text { with platelet thrombi }(T) \ddagger\end{array}$} & \multicolumn{3}{|c|}{ Surface coverage with fibrin $\S$} \\
\hline & & & On subend & On platelets & Total $(F)$ \\
\hline & $\%$ & $\%$ & $\%$ & $\%$ & $\%$ \\
\hline Normal controls $(n=8)$ & $31.8 \pm 2.8$ & $12.8 \pm 2.1$ & 0.0 & 0.0 & 0.0 \\
\hline von Willebrand's disease $(n=5)$ & $7.5 \pm 2.7^{11}$ & $2.3 \pm 1.3$ & 0.0 & 0.0 & 0.0 \\
\hline Hemophilia $(n=3)$ & $29.3 \pm 6.5$ & $12.1 \pm 1.8$ & 0.0 & 0.0 & 0.0 \\
\hline Afibrinogenemia $(n=1)$ & $54.0 \pi$ & 14.3 & 0.0 & 0.0 & 0.0 \\
\hline
\end{tabular}

B. Thrombus dimensions by planimetric morphology

\begin{tabular}{|c|c|c|c|c|c|c|}
\hline \multirow[b]{2}{*}{ Subjects } & \multirow[b]{2}{*}{ Thrombus volume } & \multicolumn{4}{|c|}{ Thrombus height distribution** } & \multirow{2}{*}{$\begin{array}{l}\text { Maximum } \\
\text { thrombus height }\end{array}$} \\
\hline & & $5-10 \mu \mathrm{m}$ & $10-20 \mu \mathrm{m}$ & $20-40 \mu \mathrm{m}$ & $>40 \mu \mathrm{m}$ & \\
\hline & $\mu m^{3} / \mu m^{2}$ & & & & & $\mu m$ \\
\hline Normal controls $(n=8)$ & $3.8 \pm 0.5$ & $76 \pm 12$ & $65 \pm 8$ & $44 \pm 3$ & $35 \pm 9$ & $75 \pm 7$ \\
\hline von Willebrand's disease & $0.3 \pm 0.2 \ddagger \ddagger$ & $13 \pm 7^{11}$ & $19 \pm 12$ & $1 \pm 1^{\prime \prime}$ & $0 \pm 0^{\prime \prime}$ & $11 \pm 3^{\| \prime}$ \\
\hline C.M. & 0.4 & 8 & 19 & 3 & 0 & 20 \\
\hline V.M. & 0.2 & 9 & 9 & 0 & 0 & 10 \\
\hline A.S. & 0.9 & 41 & 66 & 3 & 0 & 19 \\
\hline D.R. & 0.1 & 2 & 1 & 0 & 0 & 4 \\
\hline P.H. & 0.0 & 7 & 0 & 0 & 0 & 4 \\
\hline Hemophilia & $2.7 \pm 0.3 \S \S$ & $73 \pm 20$ & $82 \pm 9$ & $48 \pm 4^{\| \prime \prime}$ & $19 \pm 5^{\| 11}$ & $62 \pm 6 \S \S$ \\
\hline P.R. & 2.2 & 79 & 87 & 42 & 10 & 55 \\
\hline M.B. & 3.1 & 105 & 93 & 47 & 22 & 75 \\
\hline S.G. & 3.0 & 36 & 65 & 56 & 25 & 57 \\
\hline \multicolumn{7}{|l|}{ Afibrinogenemia } \\
\hline C.Mc. & 4.4 & 52 & 100 & 63 & 16 & 62 \\
\hline
\end{tabular}

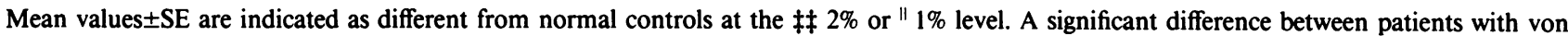
Willebrand's disease and hemophilia is indicated at the $\$ \S 2 \%$ or $\| 1 \%$ level. * The percentage of the subendothelial surface covered with platelets in either the contact $(C)$ or spread $(S)$ stage is defined as platelet adhesion $(C+S)$. $¥$ The percentage of the subendothelial surface covered with platelet thrombi extending $>5 \mu \mathrm{m}$ from the surface into the lumen is defined as surface coverage with platelet thrombi (T). $\S \mathrm{The}$ percentage of the surface, either subendothelial (subend) or platelet attached to subendothelium, covered with fibrin is defined as the total surface coverage with fibrin $(\mathrm{F})$. I Value is $>2$ SD from normal control values. ** The numbers reported for thrombus height distribution are the total number of thrombi enumerated with height in the indicated range on a cross-section of vessel segment normalized by the vessel circumference.

$<0.01)$ as compared with either normal controls or patients with severe hemophilia.

The measurements of thrombus dimensions continue to indicate the decreased $(P<0.01)$ thrombus volume and maximum thrombus height in von Willebrand's disease patients as compared with measurements in normal controls. In hemophilic patients, thrombus volume and thrombus height appear somewhat reduced as compared with those of normal controls but are not significantly decreased at these flow conditions.
Blood flow rate of $20 \mathrm{ml} / \mathrm{min}$ (wall shear rate of $1,300 \mathrm{~s}^{-1}$ ). When the blood shear rate at the wall of the vessel segment is reduced to $1,300 \mathrm{~s}^{-1}$, values of platelet adhesion $(C+S)$ in von Willebrand's disease patients become comparable to those observed in normal controls over a range of exposure times (Fig. $1 A$ ). The increase in platelet adhesion in patients with von Willebrand's disease parallels that in normal controls, and platelet adhesion appears to be asymptotic to a surface coverage of $<50 \%$ in these subjects.

In hemophilic patients, however, there appears to be a 
Table III. Interaction of Blood with Subendothelium: Blood Flowing at $40 \mathrm{ml} / \mathrm{min}\left(2,600 \mathrm{~s}^{-1}\right)$ for $2 \mathrm{~min}$

A. Standard morphometric measurements

\begin{tabular}{|c|c|c|c|c|c|}
\hline \multirow[b]{2}{*}{ Subjects } & \multirow{2}{*}{$\begin{array}{l}\text { Platelet adhesion } \\
(C+S)\end{array}$} & \multirow{2}{*}{$\begin{array}{l}\text { Surface coverage } \\
\text { with platelet thrombi }(T)\end{array}$} & \multicolumn{3}{|c|}{ Surface coverage with fibrin } \\
\hline & & & On subend & On platelets & Total (F) \\
\hline & $\%$ & $\%$ & $\%$ & $\%$ & $\%$ \\
\hline Normal controls $(n=14)$ & $30.9 \pm 2.3$ & $13.1 \pm 1.1$ & $5.8 \pm 3.2$ & $2.3 \pm 1.4$ & $8.1 \pm 4.5$ \\
\hline von Willebrand's disease $(n=5)$ & $10.6 \pm 2.0^{\prime \prime}$ & $2.6 \pm 0.3^{\| \prime}$ & 0.0 & 0.0 & 0.0 \\
\hline Hemophilia $(n=6)$ & $28.9 \pm 3.5 \S \S$ & $9.2 \pm 1.3 \S \S$ & $0.5 \pm 0.4$ & $0.1 \pm 0.1$ & $0.6 \pm 0.5$ \\
\hline Afibrinogenemia $(n=1)$ & 28.7 & 7.7 & 0.0 & 0.0 & 0.0 \\
\hline
\end{tabular}

B. Thrombus dimensions by planimetric morphology

\begin{tabular}{llc}
\hline Subjects & Thrombus volume & Maximum thrombus height \\
\hline & $\mu \mathrm{m}^{3} / \mu m^{2}$ & $\mu m$ \\
Normal controls $(n=14)$ & $3.6 \pm 0.4$ & $64 \pm 4$ \\
von Willebrand's disease $(n=5)$ & $0.5 \pm 0.1^{11}$ & $22 \pm 6^{\| 1}$ \\
Hemophilia $(n=6)$ & $2.2 \pm 0.3^{11}$ & $50 \pm 7$ \\
Afibrinogenemia $(n=1)$ & 2.0 & 44 \\
\hline
\end{tabular}

See legend to Table II for definition of C, S, T, and F. Mean values \pm SE are significantly different from normal controls at $\ddagger 2 \%$ or " $1 \%$ level. A significant difference between patients with von Willebrand's disease and hemophilia is indicated at the $\$ \$ 2 \%$ or $\| 1 \%$ level. Thrombus height distribution was not determined at this set of conditions. Subend, subendothelium.

different, higher asymptote, which results in values of platelet adhesion $(C+S)(67.0 \%)$ that appear increased as compared with those of normal controls $(41.9 \%)$ or von Willebrand's patients $(44.3 \%)$ at an exposure time of $10 \mathrm{~min}$. One factor that probably influences the asymptotic value is the rate of deposition of fibrin on subendothelium, which competes for surface coverage with platelet adhesion $(C+S)$. At the longest exposure time of $10 \mathrm{~min}$, very little fibrin is deposited on subendothelium exposed to hemophilic blood (1.3\%), as compared with deposition when blood from either von Willebrand's patients $(40.6 \%)$ or normal controls $(75.0 \%)$ is used (Fig. 1 C). (Adhesion is defined as attachment only to subendothelium; the presence of fibrin strands at the surface precludes the adhesion of platelets to subendothelium but not to fibrin.)

Under these flow conditions the technique previously used to determine thrombus formation (T) suggests no defect in the ability of platelet thrombi to cover the subendothelial surface in von Willebrand's disease (Fig. $1 B$ ); on the contrary, surface coverage with platelet thrombus $(T)$ appears greater in von Willebrand's disease patients than in normal controls or in hemophilic patients for exposure times of $\geq 3 \mathrm{~min}$.

However, inspection of the resultant deposition of blood elements on the subendothelium under these flow conditions, shown in Fig. 2, indicates that the thrombus dimensions in von Willebrand's disease are significantly reduced. The alteration in thrombus dimensions in von Willebrand's disease can be better illustrated by use of the planimetric analysis technique.
At an exposure time of $3 \mathrm{~min}$, as indicated in Table IV, maximum thrombus height, but not thrombus volume, is observed to be significantly decreased $(P<0.01)$ in von Willebrand's disease patients ( $25 \mu \mathrm{m}$ and $1.9 \mu \mathrm{m}^{3} / \mu \mathrm{m}^{2}$, respectively) as compared with control subjects (54 $\mu \mathrm{m}, 2.0 \mu \mathrm{m}^{3} / \mu \mathrm{m}^{2}$, respectively) or hemophilic patients $\left(38 \mu \mathrm{m}, 1.4 \mu \mathrm{m}^{3} / \mu \mathrm{m}^{2}\right.$, respectively.) The thrombus height distribution indicates significantly fewer thrombi $>40 \mu \mathrm{m}$ in height $(P<0.01)$ and a tendency for increased thrombi with heights between 10 and $20 \mu \mathrm{m}$ in von Willebrand's disease. The apparent shift in the growth distribution of platelet thrombi observed in von Willebrand's disease is indicated in Fig. 3.

The thrombus volume and maximum thrombus height are shown graphically for exposure times up to $10 \mathrm{~min}$ in Fig. 4. Both thrombus dimensions grow at a rate that increases with exposure time. Beyond $3 \mathrm{~min}$ of exposure, both parameters are reduced in von Willebrand's disease patients as compared with either control subjects or hemophilic patients. The reduction in thrombus height is highly significant $(P<0.01)$ as compared with normal controls.

Under these shear conditions, some decrease in thrombus volume and maximum thrombus height is also noted in the hemophilic patients, but is not statistically significant, as compared with normal controls (Fig. $4 A$ and $B$ ). The reduction in thrombus dimensions is significantly less in hemophilic patients than that observed in the von Willebrand's disease patients, even though the deposition of fibrin (Fig. $1 \mathrm{C}$ ), and 

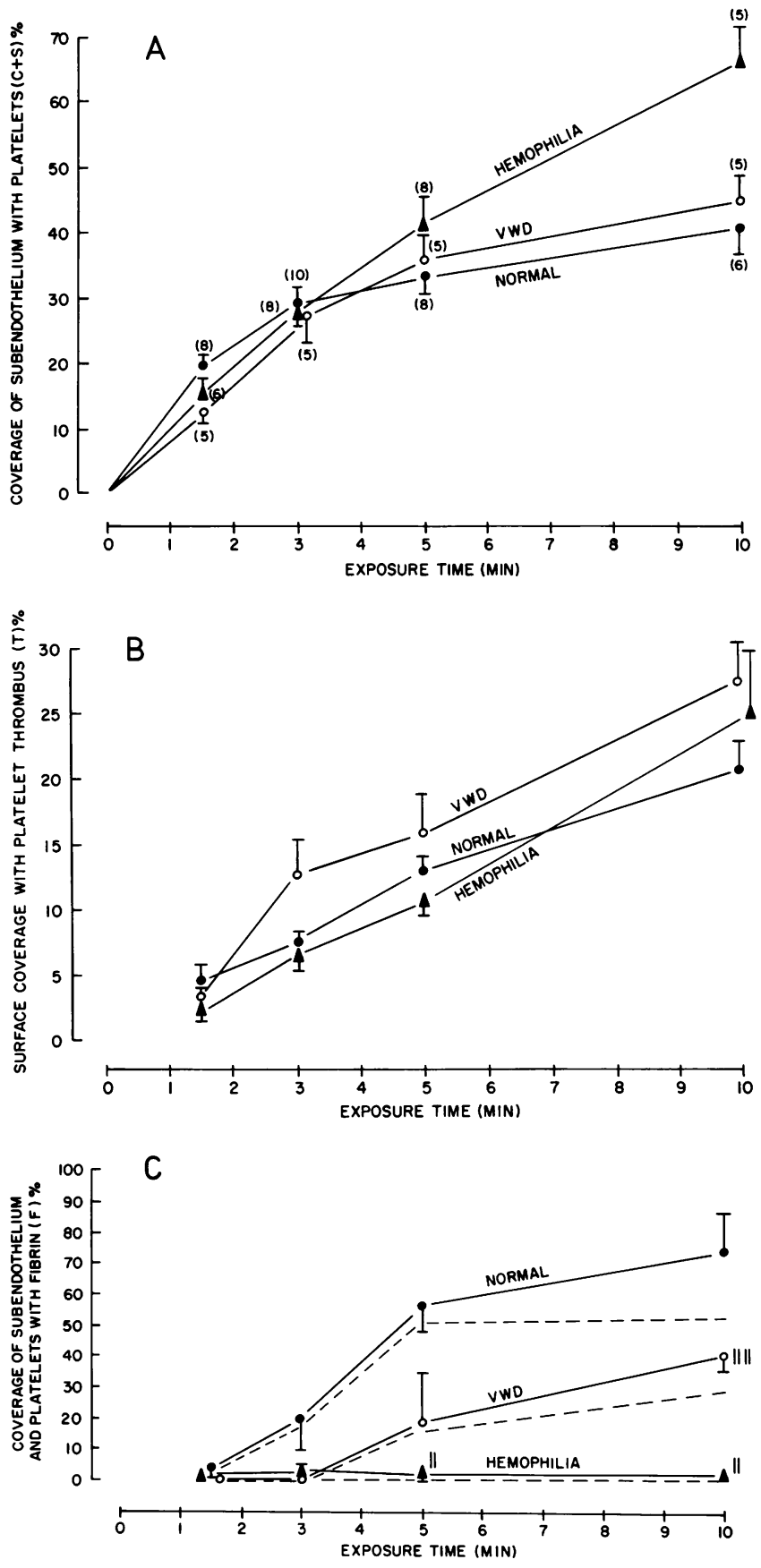

Figure 1. Blood interaction with subendothelium in von Willebrand's disease (VWD) and hemophilia. Nonanticoagulated blood flowing at $20 \mathrm{ml} / \mathrm{min}$ (wall shear rate of $1,300 \mathrm{~s}^{-1}$ ) from the anticubital vein of normal subjects $(\bullet)$ or patients with von Willebrand's disease $(0)$ or hemophilia ( $\Delta$ ) was exposed for various periods of time to everted rabbit aorta denuded of its endothelial lining. A standard morphometric technique was used to quantify the percentage of the subendothelial surface covered with $(A)$ platelets and $(B)$ platelet thrombi $>5$ $\mu \mathrm{m}$ high. $(C)$ The percentage of the subendothelial surface (dashed line) and both the subendothelial and platelet surfaces (solid line) presumably the generation of procoagulant products, is virtually absent in hemophilia.

Thrombus volume, maximum thrombus height, and thrombus height distribution in the fibrinogen-deficient patient are not significantly different from those of normal control subjects, suggesting that some factor not related to fibrinogen or fibrin formation influences thrombus formation.

Blood flow of $10 \mathrm{ml} / \mathrm{min}$ (wall shear rate of $650 \mathrm{~s}^{-1}$ ). At the lowest wall shear rates used in these experiments, the pattern of platelet and fibrin interaction (Table $\mathrm{V}$ ) is similar to that observed at $20 \mathrm{ml} / \mathrm{min}$ (Fig. 1). Platelet adhesion (C $+S)$ in von Willebrand's disease is comparable to normal control values and increased in hemophilia, especially after 10 min of exposure. Fibrin formation $(F)$ on the surface of platelets and subendothelium is very low in hemophilic patients, intermediate in von Willebrand's disease patients, and high in normal controls (Table V) at both exposure times. Surface coverage with platelet thrombus $(T)$ is not significantly different in any of these subject groups; however, thrombus volume and maximum thrombus height are decreased in both hemophilic and von Willebrand's patients, as compared with values in normal controls. These values are statistically significant $(P$ $<0.02)$ in hemophilic subjects, but only maximum thrombus height at $10 \mathrm{~min}$ of exposure is significant $(P<0.01)$ in von Willebrand's disease patients. In contrast to the results at 20 $\mathrm{ml} / \mathrm{min}$ (Fig. 4), both thrombus volume and maximum thrombus height in hemophilic patients are equal to or less than values found in von Willebrand's patients, although the differences between patient groups are not statistically significant.

The fibrinogen-deficient patient was found to be normal for all morphometric measurements, except fibrin deposition, under these flow conditions.

\section{Discussion}

In the present study, we have investigated the influence of both exposure time and blood flow rate (wall shear rate) on the interaction of blood with rabbit aorta subendothelium. Nonanticoagulated blood drawn directly from the antecubital vein was obtained from normal subjects, patients with von Willebrand's disease and hemophilia, and a single patient with severe fibrinogen deficiency.

Platelet-platelet abnormality in von Willebrand's disease. The results of this investigation confirm the previous observations that a platelet defect exists in von Willebrand's disease that is associated with platelet attachment to subendothelium (1) and that this defect in adhesion increases with increasing blood shear rate (2). The normalization of platelet adhesion $(C+S)$ in von Willebrand's disease at shear rates $<1,300 \mathrm{~s}^{-1}$

covered with fibrin are also shown. Mean values with standard error are indicated; the number of subjects used at each condition is shown in parentheses in $A$. Symbols indicate a statistical difference from normal controls at the $\$ \ddagger 2 \%$ and "1\% level or between patients with von Willebrand's disease and hemophilia at the $\$ \S 2 \%$ and " $1 \%$ level. 


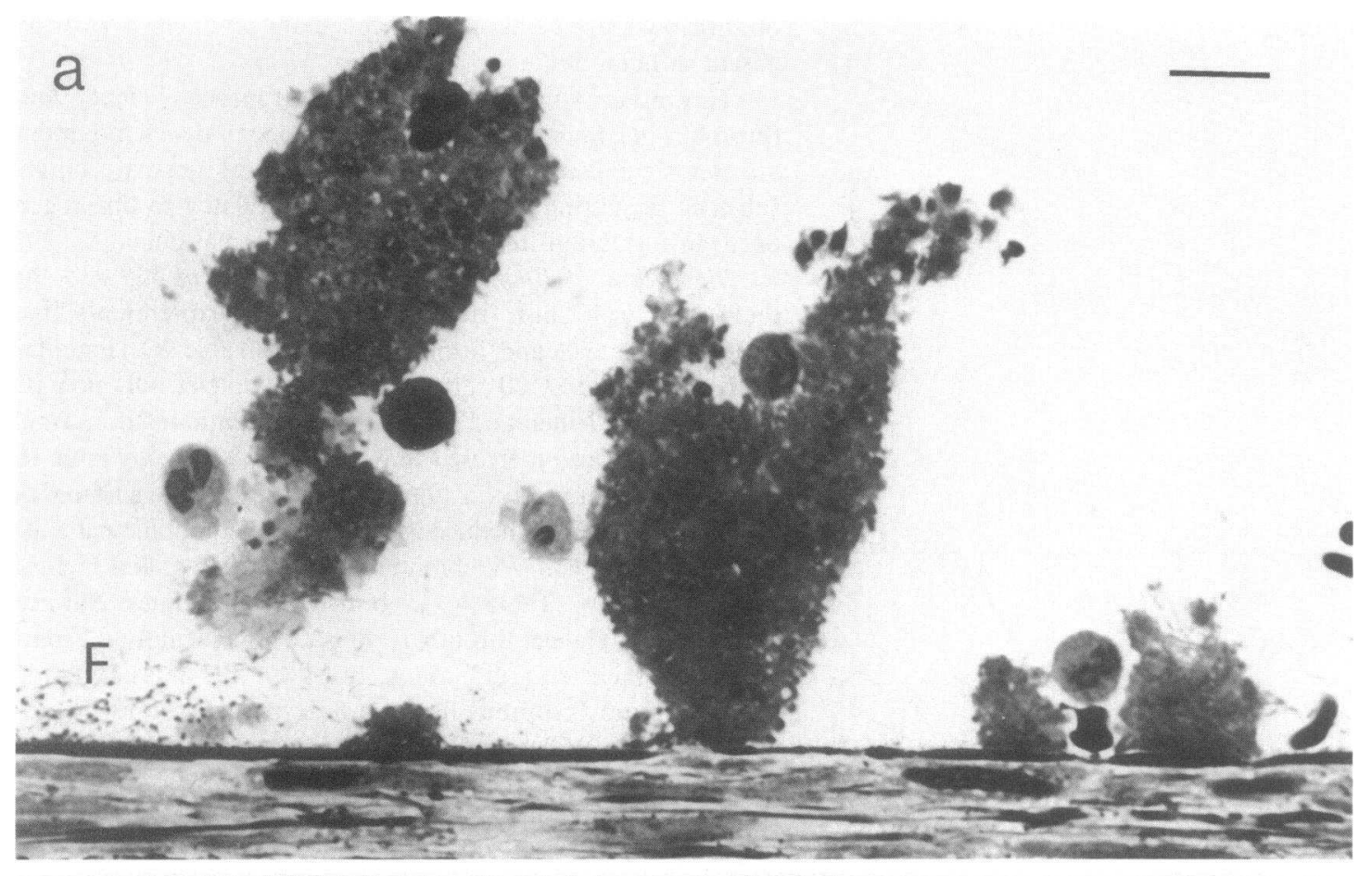

b
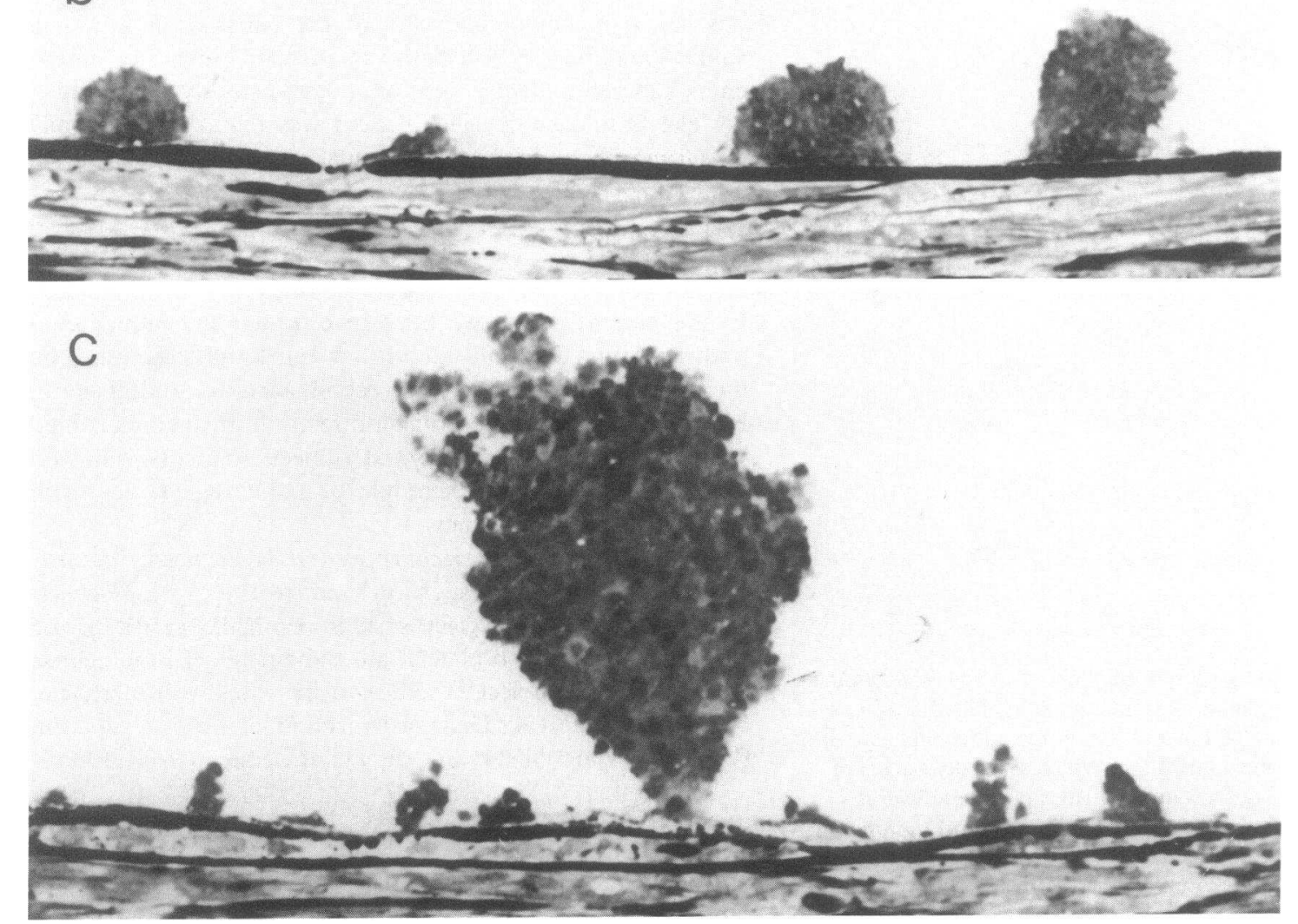
Table IV. Interaction of Blood with Subendothelium: Blood Flowing at $20 \mathrm{ml} / \mathrm{min}\left(1,300 \mathrm{~s}^{-1}\right)$ for $3 \mathrm{~min}$

A. Standard morphometric measurements

\begin{tabular}{llllll}
\hline & & & \multicolumn{2}{l}{ Surface coverage with fibrin } \\
\cline { 3 - 6 } Subjects & $\begin{array}{l}\text { Platelet adhesion } \\
(\mathrm{C}+\mathrm{S})\end{array}$ & $\begin{array}{l}\text { Surface coverage } \\
\text { with platelet thrombi }(\mathrm{T})\end{array}$ & On subend & On platelets & Total (F) \\
\hline & $\%$ & $\%$ & $\%$ & $\%$ & $\%$ \\
Normal controls $(n=10)$ & $29.4 \pm 2.8$ & $7.6 \pm 2.0$ & $16.2 \pm 7.9$ & $3.9 \pm 1.8$ & $20.1 \pm 9.6$ \\
von Willebrand's disease $(n=5)$ & $27.0 \pm 3.7$ & $12.5 \pm 2.9$ & $0.6 \pm 0.3$ & $0.1 \pm 0.1$ & $0.7 \pm 0.3$ \\
Hemophilia $(n=8)$ & $28.2 \pm 2.0$ & $6.5 \pm 1.0$ & $2.5 \pm 1.2$ & $0.6 \pm 0.3$ & $3.1 \pm 1.5$ \\
Afibrinogenemia $(n=1)$ & 37.1 & 6.4 & 0.0 & 0.0 & 0.0
\end{tabular}

B. Thrombus dimensions by planimetric morphology

\begin{tabular}{|c|c|c|c|c|c|c|}
\hline \multirow[b]{2}{*}{ Subjects } & \multirow[b]{2}{*}{ Thrombus volume } & \multicolumn{4}{|c|}{ Thrombus height distribution } & \multirow[b]{2}{*}{$\begin{array}{l}\text { Maximum } \\
\text { thrombus height }\end{array}$} \\
\hline & & $5-10 \mu \mathrm{m}$ & $10-20 \mu \mathrm{m}$ & $20-40 \mu \mathrm{m}$ & $40 \mu \mathrm{m}$ & \\
\hline & $\mu m^{3} / \mu m^{2}$ & & & & & $\mu m$ \\
\hline Normal controls $(n=10)$ & $2.0 \pm 0.2$ & $75 \pm 6$ & $56 \pm 6$ & $23 \pm 3$ & $8 \pm 2$ & $54 \pm 6$ \\
\hline von Willebrand's disease & $1.9 \pm 0.5$ & $50 \pm 4^{\prime \prime}$ & $75 \pm 14$ & $16 \pm 8$ & $0.4 \pm 0.2^{\prime \prime}$ & $25 \pm 3^{\prime \prime}$ \\
\hline C.M. & 2.4 & 50 & 82 & 13 & 1 & 24 \\
\hline V.M. & 1.4 & 46 & 76 & 9 & 0 & 24 \\
\hline A.S. & 1.2 & 58 & 52 & 7 & 0 & 21 \\
\hline D.R. & 3.6 & 38 & 123 & 47 & 1 & 35 \\
\hline P.H. & 0.9 & 57 & 42 & 3 & 0 & 22 \\
\hline Hemophilia & $1.4 \pm 0.3$ & $73 \pm 11$ & $55 \pm 9$ & $23 \pm 6$ & $6 \pm 2$ & $38 \pm 4$ \\
\hline P.R. & 2.7 & 98 & 75 & 31 & 6 & 53 \\
\hline M.B. & 0.9 & 79 & 27 & 10 & 1 & 30 \\
\hline S.G. & 1.0 & 31 & 42 & 8 & 3 & 29 \\
\hline C.C. & 1.3 & 74 & 58 & 32 & 6 & 32 \\
\hline N.V. & 2.6 & 83 & 71 & 36 & 15 & 56 \\
\hline A.B. & 1.0 & & & & & 40 \\
\hline N.B. & 1.0 & & & & & 36 \\
\hline A.C. & 0.5 & & & & & 29 \\
\hline \multicolumn{7}{|l|}{ Afibrinogenemia } \\
\hline C.Mc. & 2.2 & 53 & 42 & 19 & 6 & 46 \\
\hline
\end{tabular}

Mean values $\pm \mathrm{SE}$ are indicated as different from normal controls at the $\ddagger \ddagger$ or " $1 \%$ level. A significant difference between patients with von Willebrand's disease and hemophilia is indicated at the $\$ \S 2 \%$ or " $1 \%$ level. See legend in Table II for definition of C, S, T, and F, as well as thrombus height distribution. Subend, subendothelium.

(Fig. $1 A$, Table $\mathrm{V}$ ) was used to investigate the influence of FVIII/VFW on platelet-platelet interactions (thrombus formation) at conditions that are independent of the defect in platelet adhesion.

At the shear rates of 650 and $1,300 \mathrm{~s}^{-1}$, platelet adhesion

Figure 2. Typical blood interaction with subendothelium in normal subjects $(a)$ compared with patients with von Willebrand's disease $(b)$ or hemophilia $(c)$. Vessel segments were exposed to nonanticoagulated blood flowing at $20 \mathrm{ml} / \mathrm{min}$ (wall shear rate of $1,300 \mathrm{~s}^{-1}$ ) for 5 $\mathrm{min}$. Note the reduced height and cross-sectional area of the platelet in von Willebrand's disease patients is not significantly different from that in control subjects (Fig. $1 A$, Table V). The decreased thrombus dimensions at these conditions thus are not related to the defect in platelet-subendothelial attachment, but they suggest an impairment of platelet-platelet association, which is

thrombi in von Willebrand's disease, as well as their more hemispherical shape, as compared with the irregular growth of thrombi in either normal controls or hemophilia. Fibrin deposition (F) is indicated. Line indicates $10 \mu \mathrm{m}$. 


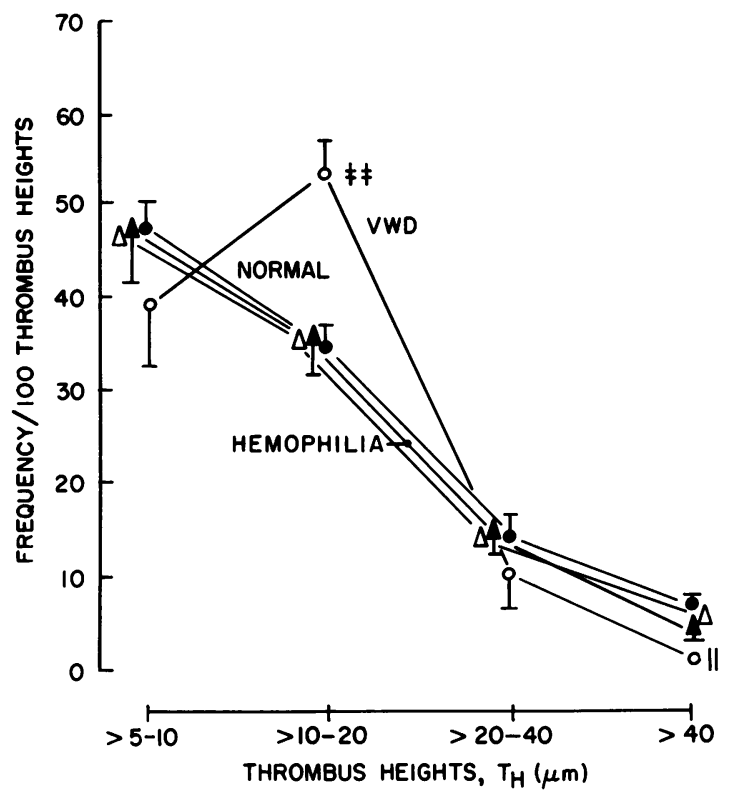

Figure 3. Thrombus height distribution on subendothelium in patients with hemophilia (৫), von Willebrand's disease (VWD) (0), and afibrinogenemia $(\Delta)$ as compared with normal subjects $(\bullet)$. Vessel segments were exposed to nonanticoagulated blood at $20 \mathrm{ml} / \mathrm{min}$ (wall shear rate of $1,300 \mathrm{~s}^{-1}$ ) for $3 \mathrm{~min}$. The height of each platelet thrombus was determined morphometrically and grouped as indicated on the abscissa. Mean values were determined after normalization of each group number by the total number of platelet thrombi on each vessel segment and are shown together with the standard error. Symbols indicate a statistical difference from normal controls at the $\ddagger \ddagger 2 \%$ and " $1 \%$ level or between patients with von Willebrand's disease and hemophilia at the $\$ \S 2 \%$ and $" 11 \%$ level.

necessary for thrombus formation and which is attributable to the reduced levels of the Factor VIII complex in these patients.

The decreased thrombus dimensions observed predominantly at lower shear conditions in hemophilia indicate that Factor VIII:C can mediate the growth and/or stability of platelet thrombi to some extent (Fig. $4 \mathrm{~A}$, Table V). It is highly likely that the impaired formation of thrombin (or other coagulation intermediates) rather than fibrin accounts for the defect, since under most conditions studied, thrombus dimensions in the afibrinogenemic patient are normal (Tables II-V). At the intermediate shear rate of $1,300 \mathrm{~s}^{-1}$, thrombus dimensions in von Willebrand's disease patients are significantly reduced as compared with those in both normal controls and hemophilic patients (Fig. $4 A$ and $B$ ), even though values of fibrin formation are considerably reduced in hemophilic compared with von Willebrand's disease patients (Fig. $1 \mathrm{C}$ ). Thus, VIII/VWF appears to be involved in the ability of platelets to attach to each other to form platelet thrombi.

We consider that the defect in thrombus dimensions in von Willebrand's disease is not attributable to the defect in platelet adhesion in this disorder primarily because platelet adhesion is normal at the conditions under which the thrombus formation remains abnormal. It is unlikely that the reduced dimensions arise from any delay in thrombus growth incurred by the reduced values of platelet adhesion observed in von Willebrand's disease at short exposure times $(1.5 \mathrm{~min}$, Fig. 1 $A$ ), since thrombus dimensions at this exposure time are in fact not significantly different from control values (Fig. $4 \mathrm{~A}$ and $B$ ), and the rate of increase in thrombus volume and maximum thrombus height in von Willebrand's disease patients remains decreased below that of normal controls, even after values of platelet adhesion $(C+S)$ become normal. However, due to the complexity of the interactions between thrombus formation and platelet adhesion and the present state of understanding of the dynamics of these events, we cannot rule out the possibility that an alternative explanation involving only platelet adhesion and Factor VIII:C could be proposed to explain the reduced levels of thrombi in von Willebrand's disease. The present investigation does not rule out the possibility that a defective mechanism subsequent to platelet adhesion, such as platelet secretion or thromboxane formation, might influence thrombus formation; however, no such defect has been reported previously in von Willebrand's disease. At present, we favor the more likely conclusion that FVIII/VWF mediates both platelet-to-subendothelial and platelet-to-platelet interactions in von Willebrand's disease.

The relatively normal values of thrombus volume in von Willebrand's disease at the short exposure times (1.5 and 3 min, Fig. $4 A$ ), together with the reduced values of thrombus height, may indicate that the initial abnormality in plateletplatelet association is not the detachment of platelet masses from the surface but the deformation of thrombi by fluid forces. Under these conditions, there is little net loss of platelet mass but a significant loss of thrombus height, which results in the apparent shift in the thrombus height distribution (Fig. 3) and the altered appearance of the platelet thrombi (Fig. 2). Such a shift is not observed in hemophilia; maximum thrombus heights are not significantly reduced from normal levels, and the appearance of platelet thrombi are normal. Levels of fibrin formation on subendothelium are low for both the von Willebrand's disease and the hemophilic patients (Fig. 1 C) and only slightly increased in the normal controls (not statistically significant) under these conditions. Thus, at these short times, the role of thrombin in thrombus stability is questionable. A more likely explanation is that the instability is due predominantly to the reduced levels of VIII/VWF in the von Willebrand's disease patients. At longer times both thrombus volume and maximum thrombus height are decreased in von Willebrand's disease (highly significant, $P<0.01$ ) and hemophilic patients and there is a net loss of platelets from the subendothelial surface as compared with normal controls. The likeliest explanation at these exposure times is that embolization is occurring due to the disruption of platelet-platelet attachments by both $(a)$ flow forces in the absence of stabilization by thrombin in both bleeding disorders, and $(b)$ the presence of 

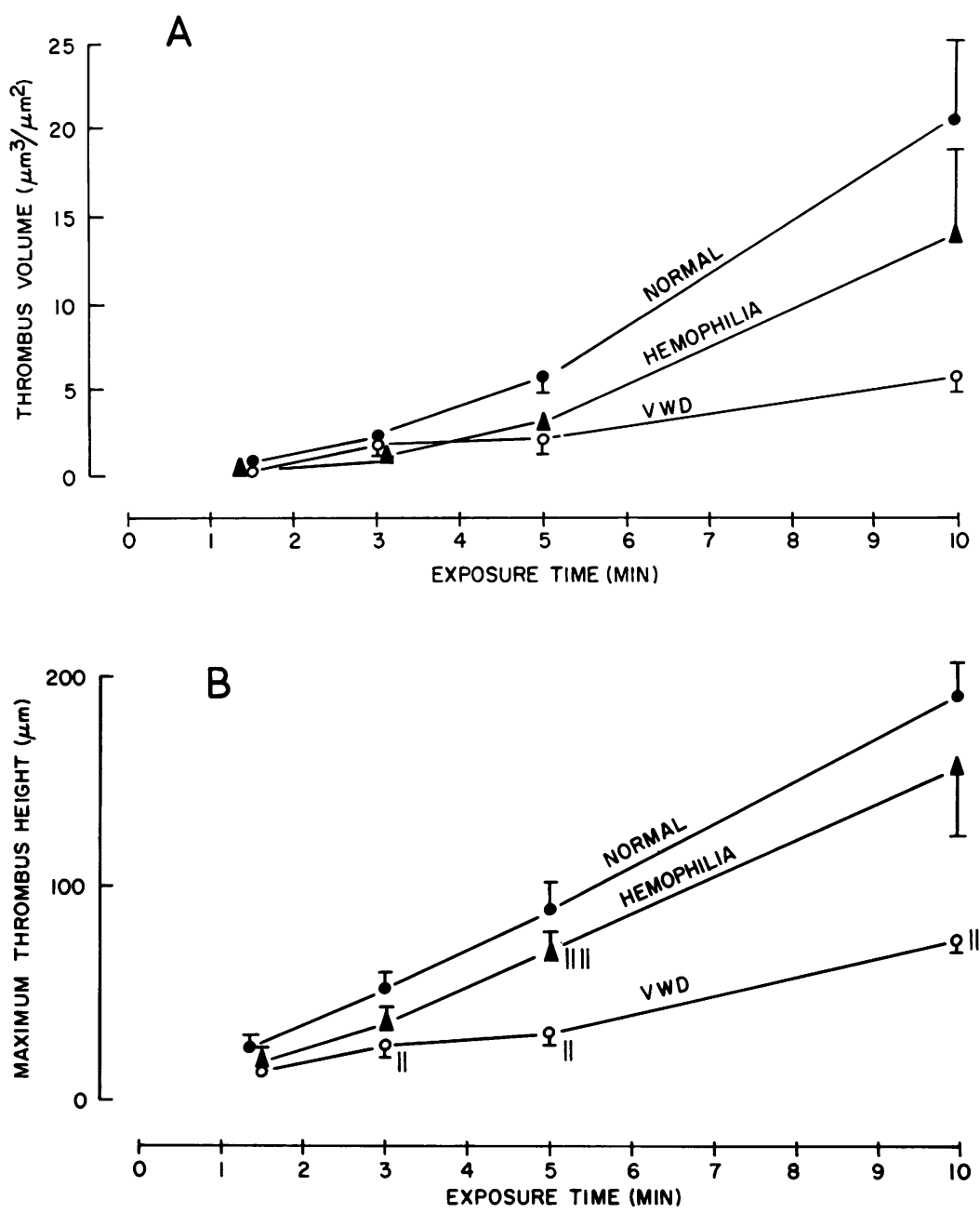

Figure 4. Blood interaction with subendothelium in von Willebrand's (VWD) disease and hemophilia. Nonanticoagulated blood flowing at $20 \mathrm{ml} / \mathrm{min}$ (wall shear rate of $1,300 \mathrm{~s}^{-1}$ ) from the antecubital vein of normal subjects $(\bullet)$ or patients with von Willebrand's disease (O) or hemophilia ( $\triangle$ ) was exposed for various periods of time to de-endothelialized rabbit aorta. A modified morphometric technique was used to quantify the percentage of the surface covered with $(A)$ the total cross-sectional area of all adherent platelet thrombi per unit length of vessel perimeter (which corresponds stereologically to the total volume per unit area) and $(B)$ the mean height of the three tallest thrombi. Mean values with standard error are shown; the number of subjects used with each condition is shown in parentheses in Fig. $1 \mathrm{~A}$. Symbols indicate a statistical difference from normal controls at the $\ddagger \ddagger 2 \%$, and " $1 \%$ level or between patients with von Willebrand's disease and hemophilia at the $\$ \S 2 \%$, and "I"1\% level. the basic defect in platelet-platelet association, related to the reduced levels of VIII/VWF in von Willebrand's disease.

Further considerations of the Factor VIII complex, blood flow, and platelet-subendothelium interactions. In this investigation we have demonstrated that the Factor VIII complex is involved in at least three different processes that lead to the formation of platelet thrombi on vascular surfaces: platelet adhesion, platelet-platelet association, and the generation of procoagulant moieties. First, we have confirmed previous studies $(1,2)$ that reduced levels of plasma VIII/VWF result in a defect in the ability of platelets to adhere to subendothelium at shear rates that are high $\left(2,600-3,300 \mathrm{~s}^{-1}\right)$ but within those normally encountered in the microcirculation. Other studies have suggested that plasma VIII/VWF binds to subendothelium and mediates to some extent platelet adhesion (18). VIII/VWF has also been reported in the subendothelium of vessel walls (19), and inhibition of platelet adhesion has been demonstrated by means of incubating vessels with an antibody to VIII/VWF (20). The relationship between the influence of plasma and vessel wall VIII/VWF on platelet adhesion requires additional study.

The defect in platetet adhesion $(C+S)$ at high shear rates $\left(2,600\right.$ and $\left.3,300 \mathrm{~s}^{-1}\right)$ leads to the development of platelet thrombi that are severely reduced in extent of surface coverage, in height, and in total quantity. The severe abnormalities in thrombus deposition that are produced under these high shear rate conditions are probably due both to inhibition of platelet adhesion and to disruption of platelet-platelet bonding. The latter appears more sensitive to shear forces than does platelet adhesion $(C+S)$, since the formation of platelet thrombi remains abnormal at flow conditions (shear rates $<1,300 \mathrm{~s}^{-1}$ ) at which platelet adhesion in von Willebrand's disease is normal. The sensitivity of platelet-platelet interactions to shear forces parallels their sensitivity to chemical factors, such as prostacyclin. Platelet-platelet cohesion sites, but not Factor VIII binding sites on platelets, have been shown to be inhibited by prostacyclin (21). Furthermore, we have demonstrated that greater levels of prostacyclin are required to inhibit platelet 
Table V. Interaction of Blood with Subendothelium Blood Flowing at $10 \mathrm{ml} / \mathrm{min}\left(650 \mathrm{~s}^{-1}\right)$ for 5 and $10 \mathrm{~min}$

\begin{tabular}{|c|c|c|c|c|c|c|c|}
\hline \multirow[b]{2}{*}{ Subjects } & \multirow{2}{*}{$\begin{array}{l}\text { Platelet } \\
\text { adhesion } \\
\text { (C+S) }\end{array}$} & \multirow{2}{*}{$\begin{array}{l}\text { Surface coverage } \\
\text { with platelet } \\
\text { thrombi }(\mathrm{T})\end{array}$} & \multicolumn{3}{|c|}{ Surface coverage with fibrin } & \multirow[b]{2}{*}{$\begin{array}{l}\text { Thrombus } \\
\text { volume }\end{array}$} & \multirow[b]{2}{*}{$\begin{array}{l}\text { Maximum } \\
\text { thrombus height }\end{array}$} \\
\hline & & & On subend & On platelets & Total (F) & & \\
\hline & $\%$ & $\%$ & $\%$ & $\%$ & $\%$ & $\mu m^{3} / \mu m^{2}$ & $\mu m$ \\
\hline \multicolumn{8}{|l|}{$\begin{array}{l}\text { Exposure time of } \\
5 \mathrm{~min}\end{array}$} \\
\hline Normal controls & & & & & & & \\
\hline $\begin{array}{l}\quad(n=14) \\
\text { von Willebrand's }\end{array}$ & $29.7 \pm 2.8$ & $8.5 \pm 1.8$ & $55.8 \pm 5.0$ & $21.4 \pm 2.5$ & $77.2 \pm 7.5$ & $2.6 \pm 0.7$ & $75 \pm 9$ \\
\hline $\begin{array}{l}\text { disease }(n=3) \\
\text { Hemophilia }\end{array}$ & $25.8 \pm 1.7$ & $6.5 \pm 1.9$ & $33.3 \pm 3.0 \S \S$ & $11.7 \pm 3.1$ & $45.0 \pm 6.0 \S \S$ & $1.4 \pm 0.1$ & $59 \pm 14$ \\
\hline $\begin{array}{c}(n=6) \\
\text { Afibrinogenemia }\end{array}$ & $36.2 \pm 1.8$ & $5.9 \pm 0.9$ & $1.4 \pm 0.9^{\| \prime}$ & $0.3 \pm 0.3^{\prime \prime}$ & $1.7 \pm 1.1^{11}$ & $1.0 \pm 0.2 \ddagger \ddagger$ & $41 \pm 4^{\prime \prime}$ \\
\hline$(n=1)$ & 24.3 & 2.8 & 0.0 & 0.0 & 0.0 & 2.2 & 78 \\
\hline $\begin{array}{l}\text { Exposure time of } \\
10 \mathrm{~min} \\
\text { Normal controls }\end{array}$ & & & & & & & \\
\hline $\begin{array}{c}(n=13) \\
\text { von Willebrand's }\end{array}$ & $36.4 \pm 2.8$ & $11.3 \pm 1.6$ & $57.1 \pm 5.2$ & $20.7 \pm 1.6$ & $77.8 \pm 6.8$ & $11.5 \pm 3.5$ & $154 \pm 15$ \\
\hline $\begin{array}{l}\text { disease }(n=3) \\
\text { Hemophilia }\end{array}$ & $41.1 \pm 3.0$ & $11.5 \pm 0.9$ & $29.7 \pm 12.7$ & $13.9 \pm 3.8$ & $43.6 \pm 16.3$ & $3.7 \pm 0.6$ & $75 \pm 4 \ddagger \ddagger$ \\
\hline $\begin{array}{c}\quad(n=6) \\
\text { Afibrinogenemia }\end{array}$ & $65.2 \pm 4.6^{\prime \prime}$ & $11.3 \pm 1.7$ & $1.4 \pm 0.8^{\prime \prime}$ & $0.8 \pm 0.6^{\prime \prime}$ & $2.2 \pm 1.3^{\prime \prime}$ & $2.9 \pm 0.6$ & $78 \pm 16 \neq \ddagger$ \\
\hline$(n=1)$ & 40.5 & 8.8 & $0.1 \pi$ & $0.4 \pi$ & $0.5 \pi$ & 13.0 & $264 \pi$ \\
\hline
\end{tabular}

Mean values \pm SE are indicated as significantly different from normal controls at the $¥ 2 \%$ or " $1 \%$ level. A significant difference between patients with von Willebrand's disease and hemophilia is indicated at the $\$ \S 2 \%$ or "I" $1 \%$ level. See legend in Table II for definition of C, S, T, and F. Thrombus height distribution was not determined at this set of conditions. I Value is $>2$ SD different from normal control value. Subend, subendothelium.

adhesion on subendothelium than to inhibit the formation of platelet thrombi (22).

Recent studies $(23,24)$ have shown that the binding of VIII/VWF to the platelet surface can be mediated by either glycoprotein Ib (ristocetin induced) or glycoprotein IIb-IIIa (thrombin or ADP induced). The absence of VIII/VWF binding in von Willebrand's disease (due at least in part to the absence of VIII/VWF in their plasma) may be related to the diminished platelet-platelet interactions (thrombus deposition) observed in the present study. The results of the present study indicate a role for VIII/VWF in platelet-platelet interactions that is sensitive to shear conditions and exposure time. Whether the defect in platelet-platelet attachment in von Willebrand's disease is due entirely to diminished plasma levels of VIII/VWF or may be related in part to reduced VIII/VWF in platelet $\alpha$ granules remains to be determined.

It is currently held that both platelet thrombi and fibrin formation are required for the permanent arrest of bleeding. The present study demonstrates that distinct differences in thrombus generation and fibrin deposition occur in von Willebrand's disease and hemophilia in response to changes in blood shear rate. These differences could be germane to the requirements for hemostasis in various parts of the microcirculation and thereby account, in some part, for the different patterns of clinical bleeding observed in the two disorders.

\section{Acknowledgments}

We acknowledge the expert technical assistance of Thomas Hoffmann, Sachi Senrui, and Kathi Schietinger. We are grateful to Drs. Majorie Zucker (New York University), Ralph Zalusky (Beth Israel Medical Center), and Parvin Saidi (Rutgers University Medical Center) for permission to study their patients.

This work was supported in part by U. S. Public Health Service grants 27204 and 27346. A grant from The Charles Slaughter Foundation was also made available during this investigation.

\section{References}

1. Tschopp, T. B., H. J. Weiss, and H. R. Baumgartner. 1974. Decreased adhesion of platelets to subendothelium in von Willebrand's disease. J. Lab. Clin. Med. 83:296-300. 
2. Weiss, H. J., V. T. Turitto, and H. R. Baumgartner. 1978. Effect of shear rate on platelet interaction with subendothelium in citrated and native blood. I. Shear-dependent decrease of adhesion in von Willebrand's disease and the Bernard-Soulier syndrome. J. Lab. Clin. Med. 92:750-764.

3. Howard, M. A., and B. G. Firkin. 1971. Ristocetin-a new tool in the investigation of platelet aggregation. Thromb. Diath. Haemorrh. 26:362-369.

4. Salzman, E. W. 1963. Measurement of platelet adhesiveness: a simple in vitro technique demonstrating an abnormality in von Willebrand's disease. J. Lab. Clin. Med. 62:724-734.

5. Zucker, M. B., and J. McPherson. 1977. Reactions of platelets near surfaces in vitro: lessons from the platelet retention test. Ann. $N Y$ Acad. Sci. 283:128-137.

6. Fauvel, F., M. E. Grant, Y. J. LeGrand, H. Souchon, G. Tobelem, D. S. Jackson, and J. P. Caen. 1983. Interaction of blood platelets with a microfibrillar extract from adult bovine aorta: requirement for von Willebrand factor. Proc. Nat. Acad. Sci. USA 80:551554.

7. Baumgartner, H. R., V. T. Turitto, and H. J. Weiss. 1980. Effect of shear rate on platelet interaction with subendothelium in citrated and native blood. II. Relationships among platelet adhesion, thrombus dimensions and fibrin deposition. J. Lab. Clin. Med. 95:203-221.

8. Baumgartner, H. R. 1976. Effects of anticoagulation on the interaction of human platelets with subendothelium in flowing blood. Schweiz. Med. Wochenschr. 106:1367-1368.

9. Turitto, V. T. 1982. Blood viscosity, mass transport and thrombogenesis. Prog. Hemostasis Thromb. 6:139-178.

10. Turitto, V. T., and H. R. Baumgartner. 1979. Platelet interaction with subendothelium in flowing rabbit blood: effect of blood shear rate. Microvasc. Res. 17:38-54.

11. Baumgartner, H. R., R. Muggli, T. B. Tschopp, and V. T. Turitto. 1976. Platelet adhesion, release and aggregation in flowing blood: effects of surface properties and platelet function. Thromb. Haemostasis. 35:124-138.

12. Weiss, H. J., I. I. Sussman, and L. Hoyer. 1977. Stabilization of factor VIII in plasma by the von Willebrand factor: studies on posttransfusion and dissociated factor VIII and in patients with von Willebrand's disease. J. Clin. Invest. 60:390-404.

13. Weiss, H. J., G. Pietu, D. Meyer, R. Rabinowitz, J. P. Girma, and J. Rogers. 1983. Heterogeneous abnormalities in the multimeric structure, antigenic properties, and plasma/platelet content of FVIII/ VWF in classical (Type I) and three sub-types of variant (Type II) von Willebrand's disease. J. Lab. Clin. Med. 101:411-425.

14. Weiss, H. J., H. R. Baumgartner, T. B. Tschopp, V. T. Turitto, and D. Cohen. 1978. Correction by factor VIII of the impaired platelet adhesion to subendothelium in von Willebrand's disease. Blood. 51:267279.

15. Weiss, H. J., V. T. Turitto, W. J. Vicic, and H. R. Baumgartner. 1984. Fibrin formation, fibrinopeptide A release, and platelet thrombus dimensions on subendothelium exposed to flowing native blood: greater in factor XII and XI than in factor VIII and IX deficiency. Blood. 63:1004-1014.

16. Weiss, H. J., and J. Rogers. 1971. Fibrinogen and platelets in the primary arrest of bleeding-studies in two patients with congenital afibrinogenemia. N. Engl. J. Med. 285:369-374.

17. Snedecor, G. W., and W. G. Cochran. 1972. Statistical Methods. 6th ed. Iowa State University Press, Ames Iowa. 114-116.

18. Sakariassen, K. S., P. A. Bolhuis, and J. J. Sixma. 1979. Human blood platelet adhesion to artery subendothelium is mediated by Factor VIII:VWF bound to subendothelium. Nature (Lond.). 279:636-638.

19. Rand, J. H., I. I. Sussman, R. E. Gorden, S. V. Chu, and V. Solomon. 1980. Localization of Factor-VIII-related antigen in human vascular subendothelium. Blood. 55:752-756.

20. Turitto, V. T., H. J. Weiss, T. S. Zimmerman, and I. I. Sussman. Factor VIII/von Willebrand factor in subendothelium médiates platelet adhesion. Blood. In press.

21. Moake, J. L., S. S. Tang, J. D. Olsen, J. H. Troll, P. L. Cimo, and P. J. Davies. 1981. Platelets, von Willebrand factor and prostaglandin $\mathrm{I}_{2}$. Am. J. Physiol. 241:H54-H59.

22. Weiss, H. J., and V. T. Turitto. 1979. Prostacyclin (Prostaglandin $I_{2}, P I_{2}$ ) inhibits platelet adhesion and thrombus formation on subendothelium Blood. 53:244-250.

23. Fujimoto, T., and J. Hawiger. 1982. Adenosine diphosphate induces binding of von Willebrand factor to human platelets. Nature (Lond.). 297:154-156.

24. Fujimoto, T., S. O'Hara, and J. Hawiger. 1982. Thrombininduced exposure and prostacyclin inhibition of the receptor for Factor VIII/von Willebrand factor on human platelets. J. Clin. Invest. 69:12121222 . 